\title{
Thonon-les-Bains - Avenue de Champagne
}

\section{Christophe Landry}

Édition électronique
URL : http://journals.openedition.org/adlfi/14959

ISSN : 2114-0502

Éditeur

Ministère de la culture

Référence électronique

Christophe Landry, "Thonon-les-Bains - Avenue de Champagne », ADLFI. Archéologie de la France Informations [En ligne], Rhône-Alpes, mis en ligne le 29 mai 2015, consulté le 19 avril 2019. URL :

http://journals.openedition.org/adlfi/14959

Ce document a été généré automatiquement le 19 avril 2019

(c) Ministère de la Culture et de la Communication, CNRS 


\title{
Thonon-les-Bains - Avenue de Champagne
}

\author{
Christophe Landry
}

Code INSEE de la commune : 74281

Lien Atlas (MCC) :

http://atlas.patrimoines.culture.fr/atlas/trunk/index.php?

ap_theme=DOM_2.01.02\&ap_bbox=6.439;46.344;6.516;46.405

1 Le diagnostic mené en mars 2013 à Thonon-les-Bains, Avenue de Champagne, en préalable à la construction d'un ensemble immobilier de 55 logements, a permis d'appréhender une occupation antique à quelques mètres au nord de l'église médiévale de Tully. Les niveaux antiques apparaissent en moyenne sous 0,40-0,45 $\mathrm{m}$ de recouvrement. Le site est installé directement sur la terrasse tardi-würmienne dont la surface se trouve à l'altitude de $427 \mathrm{~m}$ NGF à l'est de la parcelle, et à 428,50 $\mathrm{m}$ dans la partie occidentale. L'épaisseur maximale de l'occupation reconnue atteint environ $0,50 \mathrm{~m}$, sans prendre en compte les structures fossoyées. Deux phases chronologiques semblent représentées, discriminées grâce à des ensembles céramiques très indigents mais homogènes. Un premier bâtiment ainsi qu'un tronçon de voie semblent exister dès le Haut-Empire, tandis qu'un long bâtiment est implanté au $\mathrm{IV}^{\mathrm{e}}$ ou $\mathrm{V}^{\mathrm{e}} \mathrm{s}$. apr. J.-C. dans le tiers occidental du terrain exploré et sur les parcelles voisines. Les maçonneries qui fondent le bâti sont relativement soignées, en appareil de blocs et galets liés au mortier de chaux. Une sépulture d'enfant âgé de 8 ou 9 ans est aménagée à l'intérieur du second bâtiment. L'analyse radiocarbone d'un fémur permettra de préciser la datation de l'inhumation.

De nombreux vestiges modernes parsèment l'emprise explorée, comme des fosses d'inhumation de bétail, des fosses d'épierrement, un puits ou encore un tonneau enfoui en fosse. Un mur et des matériaux de démolition enfouis directement au nord des maisons de l'ancien hameau peuvent matérialiser l'emplacement d'une maison reportée sur la mappe sarde au XVIII ${ }^{\mathrm{e}} \mathrm{s}$. En revanche, aucune trace du cimetière médiéval implanté aux abords de l'église n'a été découverte. La zone funéraire semble se trouver, selon les sources, entre l'église et le terrain sondé, ou sur les parcelles situées à l'ouest et au sud- 
ouest de la présente emprise. Rappelons que Charles Marteaux, érudit de la première moitié du $\mathrm{Xx}^{\mathrm{e}} \mathrm{s}$., situait une villa antique à Tully, précisément sur le Mas du Châtelard, petit plateau surplombant au nord-ouest le terrain abritant les vestiges mis au jour cette année. Il se basait exclusivement sur une analyse onomastique, mais le tracé d'un aqueduc reconnu en d'autres points est censé traverser ce secteur. En définitive, le site de Tully appréhendé lors de ce diagnostic est susceptible de s'apparenter à une ferme implantée en périphérie de l'agglomération antique de Thonon-les-Bains, et dont les productions pouvaient alimenter les populations habitant les actuels quartiers des Ursules et des Suets.

\section{INDEX}

Index chronologique : Antiquité, Temps Modernes

Index géographique : Rhône-Alpes, Haute-Savoie (74), Thonon-les-Bains

operation Opération préventive de diagnostic (OPD), 2013 - n OA : 2211165

Mots-clés : céramique, bâti, sépulture

Keywords : Antiquity, Modern period, pottery, tomb

\section{AUTEURS}

\section{CHRISTOPHE LANDRY}

Inrap 